\title{
Intermolecular dihydrogen bonding in VI, VII, and VIII group octahedral metal hydride complexes with water
}

\author{
KARAKKADPARAMBIL S SANDHYA ${ }^{\mathrm{b}}$, GEETHA S REMYA ${ }^{\mathrm{a}}$ and \\ CHERUMUTTATHU H SURESH ${ }^{\mathrm{a}, *}$ (1) \\ ${ }^{a}$ Chemical Sciences and Technology Division, CSIR-National Institute for Interdisciplinary Science and \\ Technology, Trivandrum, Kerala 695 019, India \\ ${ }^{\mathrm{b}}$ Government College Kariavattom, Trivandrum, Kerala, India \\ E-mail: sureshch@niist.res.in, sureshch@gmail.com
}

MS received 19 March 2018; revised 23 May 2018; accepted 24 May 2018; published online 12 July 2018

\begin{abstract}
The nature of dihydrogen bonding (DHB) in VI, VII, and VIII group octahedral metal hydride complexes with $\mathrm{H}_{2} \mathrm{O}$ has been studied systematically using quantum theory of atoms-in-molecule (QTAIM) analysis. A dihydrogen bond $(\mathrm{H} \cdots \mathrm{H})$ between hydride ligand and hydrogen of $\mathrm{H}_{2} \mathrm{O}$ is revealed in QTAIM analysis with the identification of a bond critical point (bcp). The DHB is due to the donation of electron density from the hydride ligand to the hydrogen of $\mathrm{H}_{2} \mathrm{O}$. A strong linear correlation is observed between intermolecular $\mathrm{H} \cdot \cdots \mathrm{H}$ distance $\left(\mathrm{d}_{\mathrm{HH}}\right)$ and electron density $(\rho)$ at the bcp. Structural parameters suggested the highly directional nature of DHB. Weak secondary interactions between oxygen of water and other ligands contribute significantly to the binding energy ( $\left.\mathrm{E}_{\text {int }}\right)$ of DHB complex $(2.5$ to $13.2 \mathrm{kcal} / \mathrm{mol})$. Analysis of QTAIM parameters such as kinetic- $\left(G_{\mathrm{c}}\right)$, potential- $\left(V_{\mathrm{c}}\right)$ and total electron energy density $\left(H_{\mathrm{c}}\right)$ revealed the partially covalent character of DHB in majority of the complexes while a few of them showed closed shell character typical of purely non-covalent interactions.
\end{abstract}

Keywords. Dihydrogen bond; QTAIM; metal hydrides; non-covalent interaction.

\section{Introduction}

The term "dihydrogen bond" (DHB) was first proposed by Crabtree et al., in 1996 when they investigated certain $\mathrm{N}-\mathrm{H} \cdots \mathrm{H}-\mathrm{B}$ intermolecular interactions. ${ }^{1}$ They also explored the existence of similar M-H..H-C (M, transition metals) type of unconventional hydrogen bonding and reported the internuclear $\mathrm{H} \cdots \mathrm{H}$ distance, $\mathrm{d}_{\mathrm{HH}}$ in the range 1.6-2.1 $\AA^{2}{ }^{2}$ The experimental studies disclosed that the stabilizing energy of DHB is within 3-7 kcal/ $\mathrm{mol}^{3,4}$ while considerable number of experimental and theoretical studies report on the characterization of DHB systems. ${ }^{5-9}$ Various groups have studied the distinctive features of DHB systems using spectroscopy, proton affinity measurements, and analysis of thermodynamic data. ${ }^{10-14}$ Today, DHB has been enrolled as a pretty well-understood concept in chemical bonding whereas potential new applications of DHB is getting

\footnotetext{
*For correspondence
}

unfolded in many emerging areas such as hydrogen storage, water-splitting reactions, crystal engineering, catalyst tailoring and catalysis. ${ }^{15-17} \mathrm{The} \mathrm{D}-\mathrm{H}^{\delta+} \ldots{ }^{\delta+} \mathrm{H}-$ $\mathrm{A}$ interaction, (where D and $\mathrm{A}$ are proton donors and acceptors, respectively) plays a crucial role in proton transfer processes and $\sigma$ bond metathesis reactions. ${ }^{18,19}$ Szymczak et al., reported in detail the complexation patterns of $\left(\eta^{2}-\mathrm{H}_{2}\right) / \mathrm{D} \cdots\left(\mathrm{H}_{2}\right)^{+} \cdots \mathrm{A}^{-}$ion pairs and the related dihydrogen elimination reactions. ${ }^{20}$ Belkova et al., explored the equilibrium between dihydrogen bond intermediate and associated ion paired dihydrogen complex formation in a system $\mathrm{CpRu}(\mathrm{dppe}) \mathrm{H}$ (dppe $=\mathrm{Ph}_{2} \mathrm{PCH}_{2} \mathrm{CH}_{2} \mathrm{PPh}_{2}$ ) with HA. ${ }^{10}$ Later studies in this area showed the DHB formation between two metal hydrides, as for example, $\left[\mathrm{OsH}_{2}\left(\mathrm{PMePh}_{2}\right)_{4}\right] /$ $\left[\mathrm{CpM}(\mathrm{H})(\mathrm{CO})_{3}\right]$ and $\left.\left[{ }^{\mathrm{tBu}} \mathrm{PCP}\right) \mathrm{Ni}(\mathrm{H})\right] /\left[\mathrm{CpW}(\mathrm{H})(\mathrm{CO})_{3}\right]$ $\left.{ }^{\text {tBu }} \mathrm{PCP}=2,6-\mathrm{C}_{6} \mathrm{H}_{3}\left(\mathrm{CH}_{2} \mathrm{P}_{2}^{\mathrm{tBu}}\right)_{2}\right) \cdot{ }^{21}$ Formation of intramolecular DHB has been well established in various other complex systems, such as, $\left[\mathrm{IrH}_{2}\left(\mathrm{PMe}_{3}\right)\left(2-\mathrm{NH}_{2}\right.\right.$ $\left.\left.\mathrm{C}_{6} \mathrm{H}_{4}\right)\left(\mathrm{PPh}_{3}\right)_{2}\right]^{0 /+1},\left[\operatorname{Ir}\left(\mathrm{PEt}_{2} \mathrm{Ph}\right)_{2} \mathrm{H}_{2}\left(\mathrm{PPh}_{3}\right)_{2}\left(2-\mathrm{NH}_{2} \mathrm{C}_{5} \mathrm{H}_{4}\right.\right.$

Electronic supplementary material: The online version of this article (https://doi.org/10.1007/s12039-018-1498-0) contains supplementary material, which is available to authorized users. 


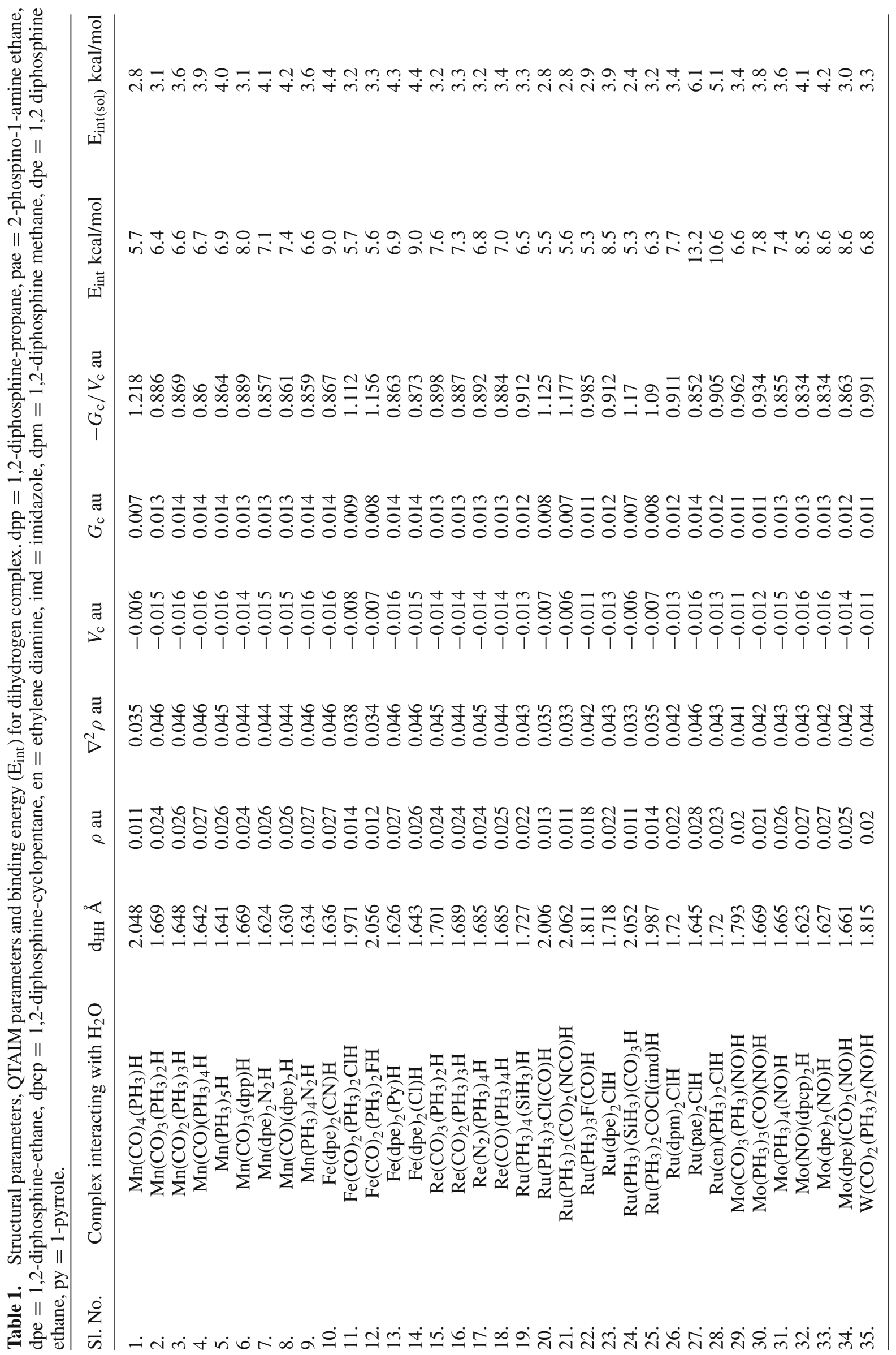


$\mathrm{N})]^{+}, \quad\left[\mathrm{IrH}_{3}\left(\mathrm{PPh}_{3}\right)_{2}\left(2-\mathrm{NH}_{2} \mathrm{C}_{5} \mathrm{H}_{4} \mathrm{~N}\right)\right], \quad\left[\operatorname{Ir}\left(\mathrm{PMe}_{3}\right)_{4}(\mathrm{H})\right.$ $(\mathrm{OH})]$ and $\left[\mathrm{Fe}(\mathrm{H})_{2}\left(\mathrm{H}_{2}\right)\left(\mathrm{PEt}_{2} \mathrm{Ph}\right)_{4}\right] .{ }^{2}$

In our previous study, the formation of $\mathrm{Ru}-\mathrm{H} \cdot \cdots \mathrm{H}-\mathrm{O}$ type DHB complex is invoked to explain the mechanism of water splitting ability of Milstein catalyst ${ }^{22}$ and several other studies showed that increasing the hydricity of $\mathrm{M}-\mathrm{H}$ bond is attractive for designing water splitting reactions of metal hydride complexes. ${ }^{17-20}$ In a recent study, we showed that hydricity of several group VI and group VII octahedral metal hydride complexes of Mo, $\mathrm{W}, \mathrm{Mn}$, and Re complexes can be quantified from the electrostatic potential minimum observed on the hydride ligand. ${ }^{23}$ These studies suggest that the $\mathrm{M}-\mathrm{H} \cdots \mathrm{H}-\mathrm{O}$ DHB interaction and the associated $\mathrm{H}_{2}$ elimination reaction is intimately connected with the nature of $\mathrm{H} \cdots \mathrm{H}$ bond. Grabowski et al., and Alkorta et al., have used quantum theory of atoms-in-molecule (QTAIM) analysis on the topographical properties of electron density at the $\mathrm{H} \cdot \cdots \mathrm{H}$ contact of small linear molecules to describe the nature of interaction as well as to find a correlation between energetic parameters and $\mathrm{d}_{\mathrm{HH}} \cdot{ }^{7,24,25}$ The nature of DHB was also studied by linear attack of small inorganic/organic molecules $\left(\mathrm{NH}_{3}, \mathrm{CH}_{4}, \mathrm{HF}\right.$, etc.) and metal hydrides such as $\mathrm{SiH}_{4}, \mathrm{LiH}, \mathrm{BeH}_{2}, \mathrm{MgH}_{2}$, etc. ${ }^{26-28} \mathrm{In}$ the present work, QTAIM analysis is used to predict the nature of dihydrogen bonding in transition metal complexes. Further, by studying $\mathrm{M}-\mathrm{H} \cdots \mathrm{H}-\mathrm{O}$ interaction, suitable hydride complexes can be proposed for efficient water-splitting reactions.

\section{Computational methodology}

The quantitative structural and bonding information was obtained from the topological QTAIM analysis proposed by Bader. ${ }^{29,30}$ The molecules were scrutinized in terms of critical points (at the critical points $\nabla \rho=0$ ). Four types of critical points were found in electron density topography, viz., $(3,-3)$ maxima, $(3,+3)$ minima, $(3,+1)$ saddle point and $(3,-1)$ saddle point. The maxima correspond to nuclear positions and a minimum appears in caged structures. Ring-shaped molecules show $(3,+1)$ saddle point while $(3,-1)$ saddle points were seen between bonded pairs of atoms. The $(3,-1)$ critical points are also called bond critical point (bcp). Laplacian of electron density at bcp, $\nabla^{2} \rho$, is another criteria for assessing the nature of the bond, which relate with kinetic $\left(V_{\mathrm{c}}\right)$ and potential $\left(G_{\mathrm{c}}\right)$ energy densities at the bcp through the local virial theorem (1),

$(1 / 4) \nabla^{2} \rho=2 G_{\mathrm{c}}+V_{\mathrm{c}}$

by which partially covalent as well as closed shell interaction can be resolved from the sign of the sum of $V_{\mathrm{c}}$ and $G_{\mathrm{c}}$. The summation $\left(V_{\mathrm{c}}+G_{\mathrm{c}}\right)$ is called the total electron energy density, $H_{\mathrm{c}}$ where a positive value represents weak 


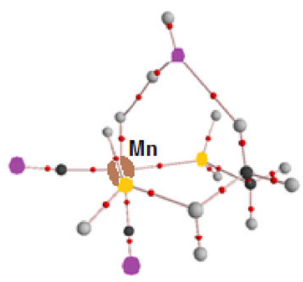

$\mathrm{Mn}(\mathrm{CO})_{3}(\mathrm{dpp}) \mathrm{H} . . . \mathrm{H}_{2} \mathrm{O}$



$\mathrm{Fe}(\mathrm{dpe})_{2}(\mathrm{CN}) \mathrm{H}_{\ldots} . . \mathrm{H}_{2} \mathrm{O}$



$\operatorname{Re}(\mathrm{CO})_{2}\left(\mathrm{PH}_{3}\right)_{3} \mathrm{H} . . . \mathrm{H}_{2} \mathrm{O}$

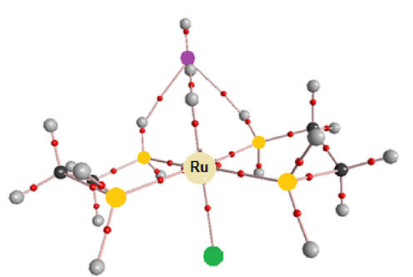

$\mathrm{Ru}(\text { pae })_{2} \mathrm{ClH} . . . \mathrm{H}_{2} \mathrm{O}$
Figure 1. Dihydrogen bond interaction and secondary interaction of some representative complexes with water are shown by QTAIM molecular graph. Atom colours: ash $=\mathrm{H}$, black $=\mathrm{C}$, purple $=\mathrm{O}$, blue $=\mathrm{N}$, green $=\mathrm{Cl}$, orange $=\mathrm{P}$ and small red sphere $=$ bcp.

or closed shell bonding and a negative value means partially covalent bond. ${ }^{30}$ Wave functions (wfn) of optimized geometry are required to estimate QTAIM parameters. All calculations were performed at B3LYP ${ }^{31,32}$ density functional theory as implemented in the Gaussian03 program. ${ }^{33}$ Effective core potential (ECP) of Hay and Wadt with an added f polarization functions were used for transition metals to replace the core electrons. ${ }^{34}$ Double- $\xi$ valence basis set (LANL2DZ) was selected for transition metals and for all other atoms 6-31G(d, p) basis set was chosen. ${ }^{34,35}$ Single point calculations at the same level were performed for describing solvation effect using SMD method. ${ }^{36}$ To reduce computation time, various bulky phosphine ligands of complexes were replaced with simple phosphine ligand $\left(\mathrm{PH}_{3}\right)$.

\section{Results and Discussion}

We have modelled Mo, W, Mn, Re, Fe and Ru metal hydride complexes comprising of various ligands in the coordination sphere. Theoretical observations of structural parameters for most of the complexes were explained in our previous paper. ${ }^{37}$ Majority of the complexes contain phosphine ligands which enhance the negative charge on the hydride ligand. Other ligands in the complexes are $\mathrm{H}_{2} \mathrm{PCH}_{2} \mathrm{CH}_{2} \mathrm{PH}_{2}, \mathrm{H}_{2} \mathrm{NCH}_{2} \mathrm{CH}_{2} \mathrm{NH}_{2}$, heterocyclic ligand, phosphine, silyl, chloro, fluoro, $\mathrm{C} \equiv \mathrm{CH}, \mathrm{NO}, \mathrm{N}_{2}$, and $\mathrm{CNO}$. All structural formulas can be seen in Table 1. The study focuses on DHB formation between the hydride ligand in the complex and hydrogen of water.

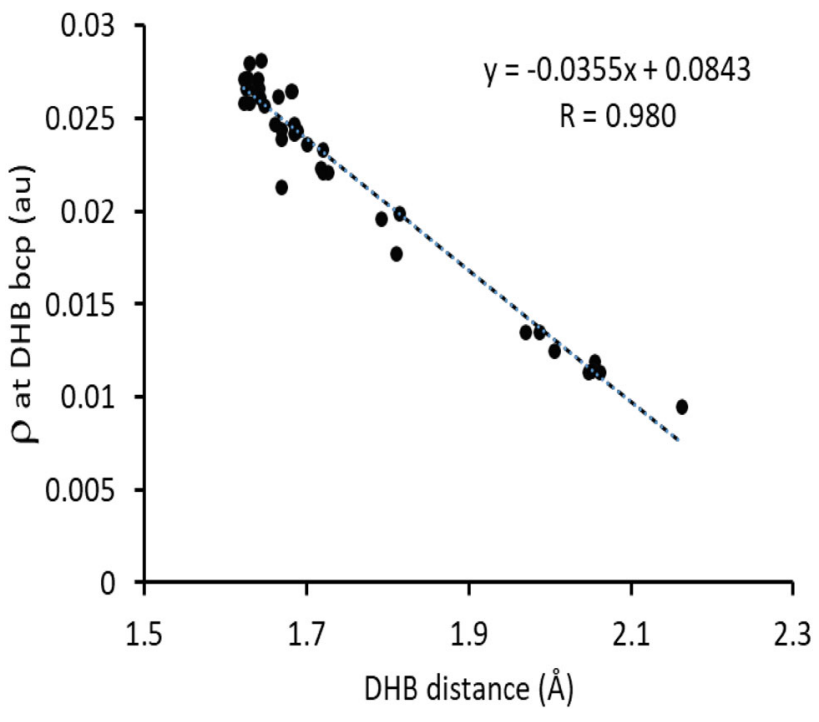

Figure 2. Correlation between $\rho$ at DHB bcp and $\mathrm{d}_{\mathrm{HH}}$.

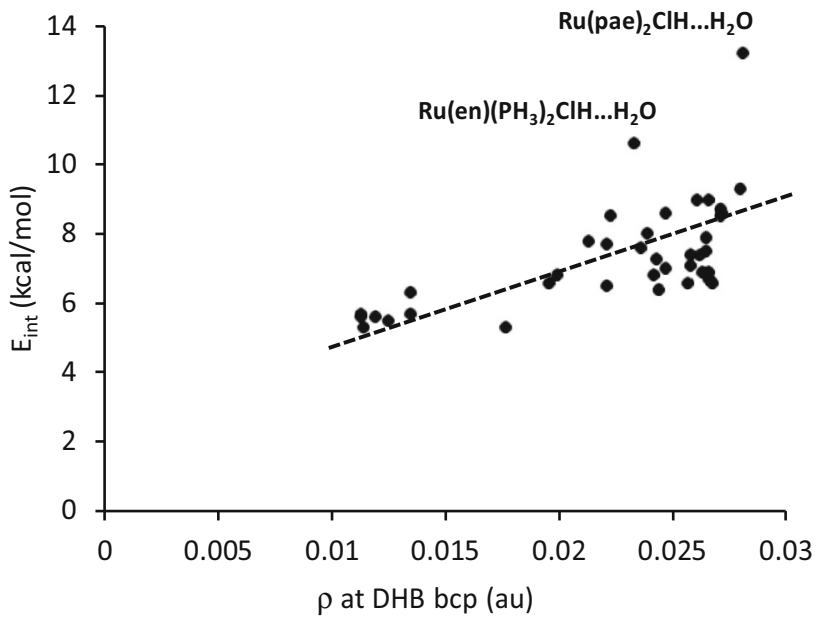

Figure 3. Correlation between $\rho$ at DHB bcp and binding energy. The two Ru complexes are not used in the linear plot.

The $\mathrm{d}_{\mathrm{HH}}$ of all complexes lies in the range $1.623 \AA-2.062 \AA$ (Table 1). This range is consistent with the distance reported for the organic and linear $\mathrm{s}$ or $\mathrm{p}$ block hydride systems as well as for many transition metal complexes. ${ }^{38-40} \mathrm{Mn}(\mathrm{CO})_{4}\left(\mathrm{PH}_{3}\right) \mathrm{H} \cdots \mathrm{H}_{2} \mathrm{O}$, $\mathrm{Re}(\mathrm{CO})_{5} \mathrm{H} \cdots \mathrm{H}_{2} \mathrm{O}, \quad \mathrm{Ru}\left(\mathrm{PH}_{3}\right)_{3} \mathrm{Cl}(\mathrm{CO}) \mathrm{H} \cdots \mathrm{H}_{2} \mathrm{O}, \quad \mathrm{Ru}$ $\left(\mathrm{PH}_{3}\right)_{2}(\mathrm{CO})_{2}(\mathrm{NCO}) \mathrm{H} \cdots \mathrm{H}_{2} \mathrm{O}$ and $\mathrm{Ru}\left(\mathrm{PH}_{3}\right)_{2}(\mathrm{CO})_{3}$ $\mathrm{H} \cdots \mathrm{H}_{2} \mathrm{O}$ complexes show higher $\mathrm{d}_{\mathrm{HH}}$ values compared to other complexes. The binding energy $\left(E_{\text {int }}\right)$ for the water adducts are in the range of 5.3 to $13.2 \mathrm{kcal} / \mathrm{mol}$, which is similar to intramolecular $\mathrm{H} \cdots \mathrm{H}$ bond strength reported by Crabtree et al. ${ }^{3,41}$ The highest $\mathrm{E}_{\text {int }}$ $10.6 \mathrm{kcal} / \mathrm{mol}$ and $13.2 \mathrm{kcal} / \mathrm{mol}$ are observed for the Ru complexes $\mathrm{Ru}(\mathrm{en})\left(\mathrm{PH}_{3}\right)_{2} \mathrm{ClH}$ and $\mathrm{Ru}(\text { pae })_{2} \mathrm{ClH}$, respectively, whereas the weakest $\mathrm{E}_{\text {int }} 5.3 \mathrm{kcal} / \mathrm{mol}$ is observed for $\mathrm{Ru}\left(\mathrm{PH}_{3}\right)_{3} \mathrm{~F}(\mathrm{CO}) \mathrm{H} \cdots \mathrm{H}_{2} \mathrm{O}$. Lower ranges of $\mathrm{E}_{\text {int }}$ correlate to larger $\mathrm{d}_{\mathrm{HH}}$ values. The binding energy of water 


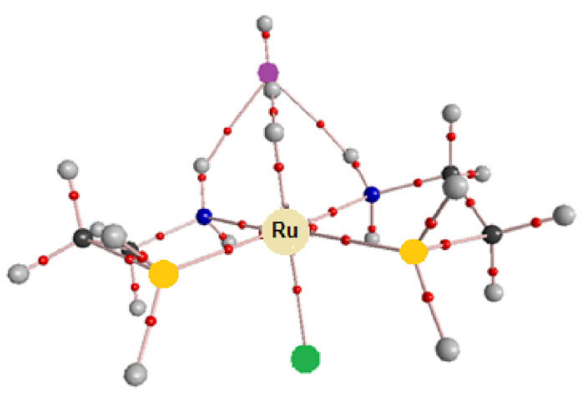

$\mathrm{Ru}(\text { pae })_{2} \mathrm{ClH} . . . \mathrm{H}_{2} \mathrm{O}$

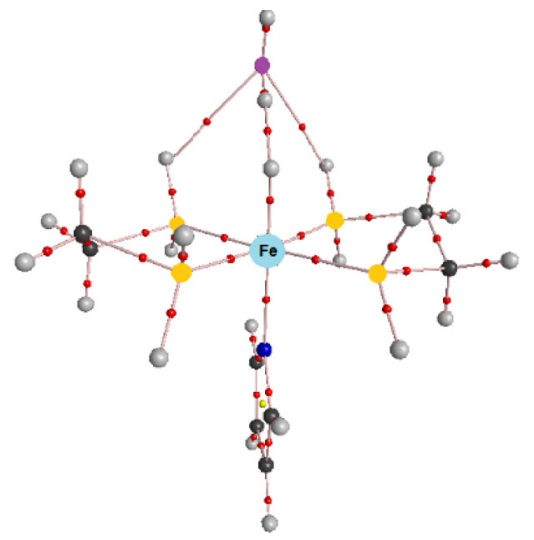

$\mathrm{Fe}(\mathrm{dpe})_{2}(\mathrm{Py}) \mathrm{H} . . . \mathrm{H}_{2} \mathrm{O}$

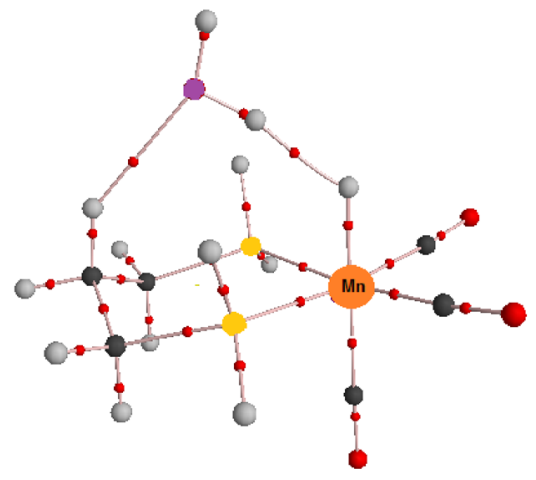

$\mathrm{Mn}(\mathrm{CO})_{3}(\mathrm{dpp}) \mathrm{H} . . . \mathrm{H}_{2} \mathrm{O}$

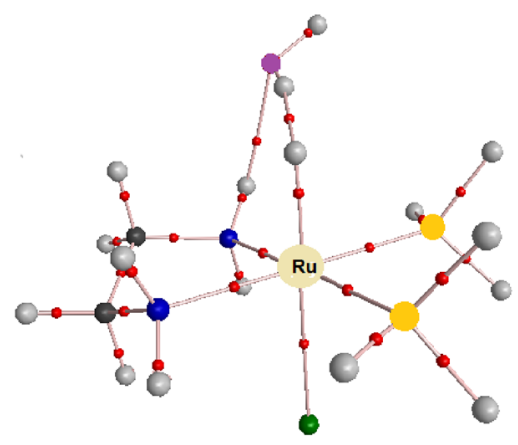

$\mathrm{Ru}(\mathrm{en})\left(\mathrm{PH}_{3}\right)_{2} \mathrm{ClH} \ldots \mathrm{H}_{2} \mathrm{O}$

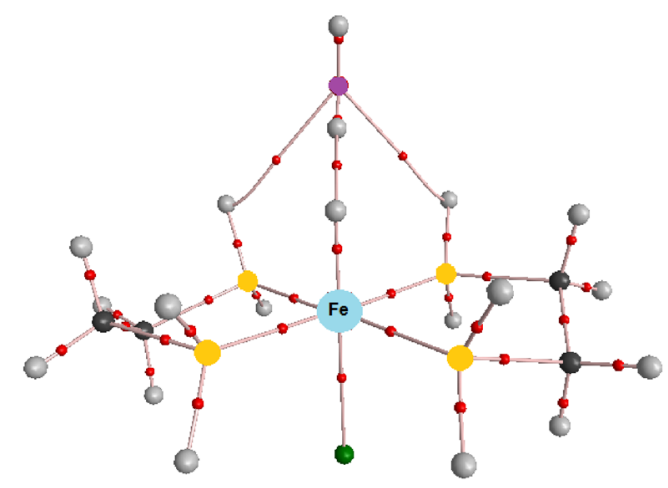

$\mathrm{Fe}(\mathrm{dpe})_{2}(\mathrm{Cl}) \mathrm{H} . . . \mathrm{H}_{2} \mathrm{O}$

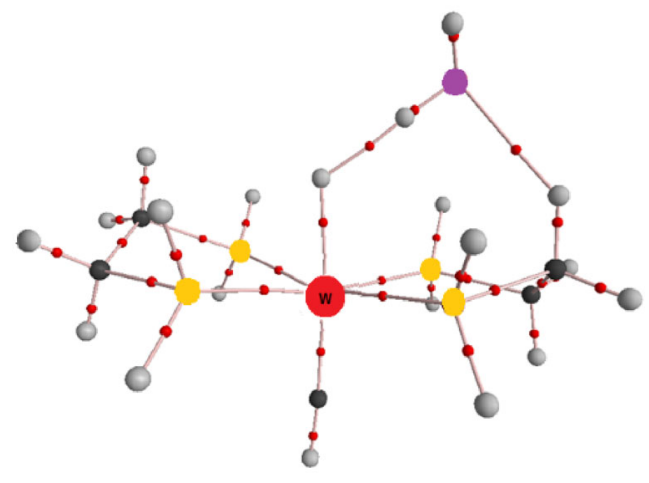

$\mathrm{W}(\mathrm{CH})(\mathrm{dpe}){ }_{2} \mathrm{H} \ldots \mathrm{H}_{2} \mathrm{O}$

Figure 4. QTAIM molecular graph of representative DHB complexes showing secondary interactions.

adducts is also calculated with the inclusion of solvent effect $\left(\mathrm{E}_{\text {int }(\mathrm{sol})}\right)$. Solvation effects decreased $\mathrm{E}_{\text {int }}$ by 50 $60 \%$ compared to the gas phase values (Table 1 ).

Molecular graph as seen in QTAIM is provided in Figure 1 for some representative cases. A bcp is observed for the H...HDHB interaction in all the complexes. The $\rho$ value at bcp for all the systems is in the range 0.0110.028 a.u. The strength of DHB is proportional to $\rho$ and it decreases with increase in $\mathrm{d}_{\mathrm{HH}}$ distance (Figure 2). The Laplacian $\nabla^{2} \rho$ of all the systems fall in this range 0.033-0.048 a.u. which is similar to the range reported by Grabowski et al., (0.049-0.016 a.u.) for a wide spectrum of dihydrogen interactions. ${ }^{42}$

The M-H. . HO type DHB formation leads to a slight elongation $(0.005 \AA-0.020 \AA)$ of $\mathrm{OH}$ bond distance of water $\left(\mathrm{d}_{\mathrm{OH}}\right)$. Further, the $\mathrm{H} \cdots \mathrm{HO}$ angle $(\theta)$ is in the range $141-179^{\circ}$ suggesting that among various possible orientations of water around the hydride ligand, a collinear approach of $\mathrm{M}-\mathrm{H}$ and $\mathrm{OH}$ bonds is mostly preferred, indicating the highly directional nature of DHB.

An increasing trend in binding energy $\left(\mathrm{E}_{\text {int }}\right)$ with an increase in the $\rho$ value at the DHB bcp is observed 
for most of the complexes (Figure 3) indicating that the water adduct formation depends on the strength of DHB energy. The deviations in the linear trend can be attributed to interactions other than DHB (secondary interactions). For instance, a noticeable deviation in the plot shown by $\mathrm{Ru}(\text { pae })_{2} \mathrm{ClH} \cdot \cdots \mathrm{H}_{2} \mathrm{O}$ can be attributed to the two $\mathrm{NH} \cdots \mathrm{OH}$, interactions as seen in the QTAIM molecular graph (Figure 4) between the oxygen of water and the $\mathrm{NH}$ bonds of the chelating ligands. Such interactions lead to significant rise in binding energy $(13.2 \mathrm{kcal} / \mathrm{mol})$. The complexes, $\mathrm{Fe}(\mathrm{dpe})_{2}(\mathrm{PY}) \mathrm{H} \cdots \mathrm{H}_{2} \mathrm{O}$ and $\mathrm{Fe}(\mathrm{dpe})_{2}(\mathrm{Cl}) \mathrm{H} \cdots \mathrm{H}_{2} \mathrm{O}$ also exhibit a similar kind of interaction between the PH bonds of the chelating ligand and oxygen of water. Similarly, the higher binding energy of $\mathrm{Ru}(\mathrm{en})\left(\mathrm{PH}_{3}\right)_{2} \mathrm{ClH} \cdots \mathrm{H}_{2} \mathrm{O}$ can be attributed to the presence of one $\mathrm{NH}$. . OH, interaction (Figure 4). A secondary interaction between a $\mathrm{CH}_{2}$ unit of a chelating ligand and oxygen of water is also possible. However, such interactions are very weak and do not significantly alter the correlation trend. Examples belonging to this class of complexes are $\mathrm{Mn}(\mathrm{CO})_{3}(\mathrm{dpp}) \mathrm{H} \cdot \mathrm{H}_{2} \mathrm{O}, \mathrm{Mn}(\mathrm{dpe})_{2} \mathrm{~N}_{2} \mathrm{H} \cdots$ $\mathrm{H}_{2} \mathrm{O}, \quad \mathrm{Fe}(\text { dpe })_{2}(\mathrm{CN}) \mathrm{H} \cdots \mathrm{H}_{2} \mathrm{O}, \quad \mathrm{Ru}($ dpe $) \mathrm{ClH} \cdots \mathrm{H}_{2} \mathrm{O}$, $\mathrm{Ru}(\mathrm{dpm})_{2} \mathrm{ClH} \cdots \mathrm{H}_{2} \mathrm{O}$ and $\mathrm{Mo}(\text { dpe })_{2}(\mathrm{NO}) \mathrm{H} \cdots \mathrm{H}_{2} \mathrm{O}$.

The positive $\nabla^{2} \rho$ values observed for all the dihydrogen complexes suggest their weak non-covalent nature and such interactions lead to the contraction of electron density towards each hydrogen nucleus. In all the cases, $\left|V_{\mathrm{c}}\right|>2 G_{\mathrm{c}}$ indicating that the interactions are non-covalent. ${ }^{30}$ According to Ziółkowski et al., a bcp showing a purely non-covalent interaction has the ratio $-G_{\mathrm{c}} / V_{\mathrm{c}}$ greater than one. ${ }^{43}$ Figure 5 gives a linear relationship between DHB bond distance and $-G_{\mathrm{c}} / V_{\mathrm{c}}$ which indicates that only eight out of forty complexes studied herein fulfil this criterion. The purely covalent to partially covalent complexes can also be distinguished well from the sign of $H_{\mathrm{c}}$ (Table 1). Positive $H_{\mathrm{c}}$ values in the range 0.000 to 0.0013 au correspond to purely noncovalent closed shell interaction while the rest in the range -0.0001 and -0.0027 a.u. can be attributed to the partially covalent interaction. ${ }^{42,44}$ The DHB complexes with $\mathrm{d}_{\mathrm{HH}}$ in the range of $1.863-2.062 \AA$ belong to purely non-covalent and those in the range 1.623-1.815 belong to partially covalent complexes (Figure 5). The partially covalent nature of the DHB is conducive for $\mathrm{H}_{2}$ elimination reactions. ${ }^{45,46}$

\section{Conclusions}

The nature of dihydrogen bonding in octahedral metal hydride complexes (metal $=\mathrm{Mn}, \mathrm{Re}, \mathrm{Mo}, \mathrm{W}, \mathrm{Fe}$ and $\mathrm{Ru}$ ) with $\mathrm{H}_{2} \mathrm{O}$ has been studied using QTAIM analysis.

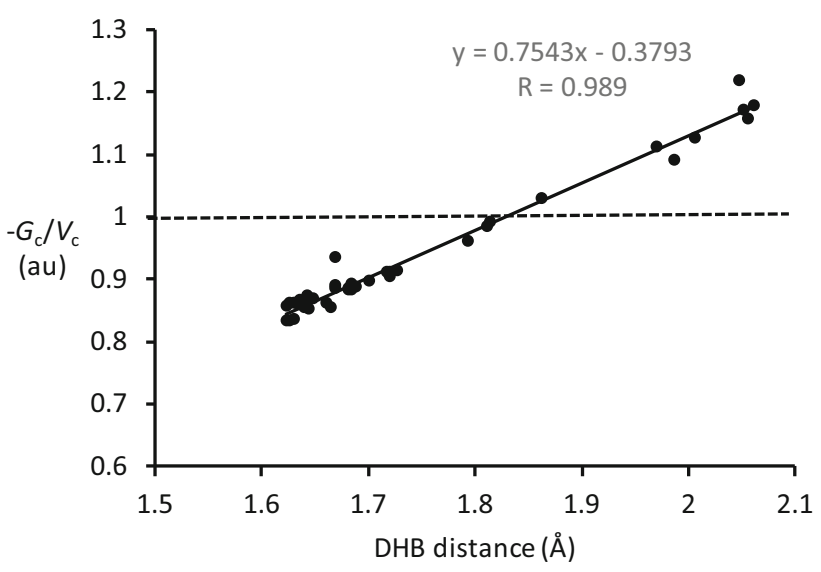

Figure 5. Correlation between QTAIM parameters and $\mathrm{d}_{\mathrm{HH}}$.

A bcp between $\mathrm{H} \cdots \mathrm{H}$ bond indicates a weak dihydrogen bond (DHB) formation between the hydrogen of water and the hydride of the metal complex. Partially covalent nature of DHB is revealed for the majority of the complexes while a few of them showed closed shell and purely non-covalent interactions. The highly directional nature of DHB is revealed through structural analysis while the energetics showed stabilizing secondary interactions between the oxygen of water and nearby ligands. The partially covalent character of DHB is helpful for promoting $\mathrm{H}_{2}$ elimination reaction from the complexes.

\section{Supporting Information (SI)}

Tables showing secondary interaction data, and coordinates of all complexes are given in supplementary information available at www.ias.ac.in/chemsci.

\section{Acknowledgements}

The authors thank CSIR, Govt. of India for financial support and CSIR-4PI for HPC support.

\section{References}

1. Richardson T B, Koetzle T F and Crabtree R H 1996 An $\mathrm{M}-\mathrm{H}$. . H-C hydrogen bonding interaction Inorg. Chim. Acta 25069

2. Crabtree R H, Siegbahn P E M, Eisenstein O, Rheingold A L and Koetzle T F 1996 A new intermolecular interaction: unconventional hydrogen bonds with elementhydride bonds as proton acceptor Acc. Chem. Res. 29 348

3. Peris E, Lee Jr J C, Rambo J R, Eisenstein O and Crabtree R H 1995 Factors affecting the strength of X-H . . H-M hydrogen bonds J. Am. Chem. Soc. 1173485

4. Desmurs P, Kavallieratos K, Yao W and Crabtree R H 1999 Intermolecular Re-H . . H-N and Re-H . . base 
hydrogen bonding estimated in solution by a uv-vis spectroscopic method New J. Chem. 231111

5. Oliveira B G and Vasconcellos M L A A 2009 A B3LYP and QTAIM study of a new proton donor for dihydrogen bonds: The case of the $\mathrm{C}_{2} \mathrm{H}_{5}^{+} \cdots \mathrm{nBeH}_{2}$ complexes $(\mathrm{n}=1$ or 2) Struct. Chem. 20897

6. Orlova $\mathrm{G}$ and Scheiner S 1998 Intermolecular H ...H bonding and proton transfer in semisandwich $\mathrm{Re}$ and $\mathrm{Ru}$ complexes J. Phys. Chem. A 1024813

7. Alkorta I, Zborowski K, Elguero J and Solimannejad M 2006 Theoretical study of dihydrogen bonds between (XH) $2, \mathrm{X}=\mathrm{Li}, \mathrm{Na}, \mathrm{BeH}$, and $\mathrm{MgH}$, and weak hydrogen bond donors (HCN, HNC, and $\mathrm{HCCH}$ ) J. Phys. Chem. A 11010279

8. Pak C, Lee H M, Kim J C, Kim D and Kim K S 2005 Theoretical investigation of normal to strong hydrogen bonds Struct. Chem. 16187

9. Grabowski S J 2000 Theoretical evidence for a new kind of intramolecular dihydrogen bond Chem. Phys. Lett. 327203

10. Belkova $\mathrm{N}$ V, Dub $\mathrm{P}$ A, Baya M and Houghton J 2007 Kinetics and thermodynamics of proton transfer to $\mathrm{Cp} * \mathrm{Ru}(\mathrm{dppe}) \mathrm{H}$ : Via dihydrogen bonding and $\left(\eta^{2}-\mathrm{H}_{2}\right)-$ complex to the dihydride Inorg. Chim. Acta 360149

11. Shubina E S, Belkova N V, Krylov A N, Vorontsov E V, Epstein L M, Gusev D G, Niedermann M and Berke H 1996 Spectroscopic Evidence for Intermolecular M-H...OR Hydrogen Bonding: Interaction of $\mathrm{WH}(\mathrm{CO})_{2}(\mathrm{NO}) \mathrm{L}_{2}$ Hydrides with Acidic Alcohols J. Am. Chem. Soc. 1181105

12. Belkova N V, Epstein L M, Krylova A I, Faerstein E G and Shubina E S 2007 Kinetics of protonation of tungsten hydrides $\mathrm{WH}(\mathrm{CO})_{2}(\mathrm{NO}) \mathrm{L}_{2}$ by weak $\mathrm{OH}$-acids Russ. Chem. Bull. 56870

13. Avramović N, Höck J, Blacque O, Fox T, Schmalle $\mathrm{H} \mathrm{W}$ and Berke $\mathrm{H} 2010$ Hydridic reactivity of $\mathrm{W}(\mathrm{CO})(\mathrm{H})(\mathrm{NO})\left(\mathrm{PMe}_{3}\right)_{3}$ - Dihydrogen bonding and $\mathrm{H}_{2}$ formation with protic donors J. Organomet. Chem. 695 382

14. Ayllón J A, Gervaux C, Sabo-Etienne $\mathrm{S}$ and Chaudret B 1997 First NMR observation of the intermolecular dynamic proton transfer equilibrium between a hydride and coordinated dihydrogen: $(\mathrm{dppm})_{2} \mathrm{HRuH} \cdots \mathrm{H}-\mathrm{OR}=\left[(\mathrm{dppm})_{2} \mathrm{HRu}\left(\mathrm{H}_{2}\right)\right]+(\mathrm{OR})$ Organometallics 162000

15. Bakhmutov V I 2007 Dihydrogen Bonds: Principles, Experiments, and applications (NJ, USA: Wiley)

16. Morris R H 2016 Brønsted-Lowry acid strength of metal hydride and dihydrogen complexes Chem. Rev. 1168588

17. Belkova N V, Epstein L M, Filippov O A and Shubina E S 2016 Hydrogen and dihydrogen bonds in the reactions of metal hydrides Chem. Rev. 1168545

18. Custelcean R, and Jackson J E 2001 Dihydrogen bonding: structures, energetics, and dynamics Chem. Rev. 101 1963

19. Li W Z, Liu T, Cheng J B, Li Q Z and Gong B A 2010 Theoretical investigation on $\mathrm{H}_{2}$ elimination reactions of germylenoid $\mathrm{H}_{2} \mathrm{GeLiF}$ with $\mathrm{RH}\left(\mathrm{R}=\mathrm{F}, \mathrm{OH}\right.$, and $\left.\mathrm{NH}_{2}\right)$ J. Organomet. Chem. 695909

20. Szymczak N K and Tyler D R 2008 Aspects of dihydrogen coordination chemistry relevant to reactivity in aqueous solution Coord. Chem. Rev. 252212
21. Levina V A, Rossin A, Belkova N V, Chierotti M R, Epstein L, Filippov O A, Gobetto R, Gonsalvi L, Lledõs A, Shubina E S, Zanobini $F$ and Peruzzini M 2011 Acid-base interaction between transition-metal hydrides: Dihydrogen bonding and dihydrogen evolution Angew. Chem. Int. Ed. 501367

22. Sandhya K S and Suresh C H 2011 Water splitting promoted by a ruthenium(II) PNN complex: An alternate pathway through a dihydrogen complex for hydrogen production Organometallics 303888

23. Sandhya K S and Suresh C H 2017 Quantification of Thermodynamic Hydridicity of Hydride Complexes of Mn, Re, Mo, and W Using the Molecular Electrostatic Potential J. Phys. Chem. A 1212814

24. Grabowski S J, Sokalski W A and Leszczynski J 2007 Wide spectrum of $\mathrm{H} \cdots \mathrm{H}$ interactions: van der Waals contacts, dihydrogen bonds and covalency Chem. Phys. 33768

25. Grabowski S J, Sokalski W A and Leszczynski J 2005 How short can the $\mathrm{H} \cdot \mathrm{H}$ intermolecular contact be? New findings that reveal the covalent nature of extremely strong interactions J. Phys. Chem. A 1094331

26. Hubert C, Magdalena P and Joanna S H T 2003 Characterization of dihydrogen bonded DH-H-A complexes $J$. Chem. Phys. 1195094

27. Zhu W L, Puah C M, Tan X-J, Jiang H-L and Chen K-X 2001 Quantum chemistry investigation on the dihydrogen bond between silicane and ammonium J. Phys. Chem. A $\mathbf{1 0 5} 426$

28. Sławomir J G 2000 High-level Ab-initio calculations of dihydrogen-bonded complexes J. Phys. Chem. A 104 5551

29. Bader R F W 1989 Atoms in molecules in external fields J. Chem. Phys. 916989

30. Kumar P S V, Raghavendra V and Subramanian V 2016 Bader's theory of atoms in molecules (AIM) and its applications to chemical bonding J. Chem. Sci. 1281527

31. Becke A D 1993 J. Chem. Phys. 985648

32. Lee C, Yang W and Parr R G 1988 Development of the Colle-Salvetti correlation-energy formula into a functional of the electron density Phys. Rev. B 37785

33. Frisch M J, Trucks G W 2004 Gaussian 03, Revision E.01; Gaussian, Inc: Wallingford CT

34. Hay P J and Wadt W R 1985 Ab initio effective core potentials for molecular calculations. Potentials for the transition metal atoms $\mathrm{Sc}$ to $\mathrm{Hg}$ Chin. J. Chem. Phys. 82 270

35. Hariharan P C and Pople J A 1973 The influence of polarization functions on molecular orbital hydrogenation energies Theor. Chim. Acta 28213

36. Marenich A V, Cramer C J and Truhlar D G 2009 Universal solvation model based on solute electron density and on a continuum model of the solvent defined by the bulk dielectric constant and atomic surface tension J. Phys. Chem. B 1136378

37. Sandhya K S and Suresh C H 2014 Designing metal hydride complexes for water splitting reactions: a molecular electrostatic potential approach Dalton Trans. 43 12279

38. Alkorta I, Zborowski K, Jose Elguero J and Solimannejad M 2006 Theoretical study of dihydrogen bonds between $(\mathrm{XH})_{2}, \mathrm{X} \mathrm{Li}, \mathrm{Na}, \mathrm{BeH}$, and $\mathrm{MgH}$, and weak 
hydrogen bond donors (HCN, HNC, and HCCH) J. Phys. Chem. A 11010279

39. Grabowski J S 2006 Theoretical studies of strong hydrogen bonds Annu. Rep. Prog. Chem., Sect. C 102 131

40. Orlova G, Scheiner S and Kar T 1999 Activation and cleavage of $\mathrm{H}-\mathrm{R}$ bonds through intermolecular $\mathrm{H}-\mathrm{H}$ bonding upon reaction of proton donors HR with 18electron transition metal hydrides J. Phys. Chem. A 103 514

41. Crabtree R H 2016 Dihydrogen complexation Chem. Rev. 1168750

42. Grabowski S J 2001 An abitio calculations on conventional and uncoventional hydrogen bonds J. Phys. Chem. A 10510739
43. Ziolkowski M, Grabowski S J and Leszczynski J 2006 Cooperativity in hydrogen-bonded interactions: Ab initio and "atoms in molecules" analyses J. Phys. Chem. A 110514

44. Calhorda M J and Lopes P E M 2000 An atoms in molecules analysis of the dihydrogen bond in the organometallic compounds J. Organomet. Chem. 60953

45. Sandhya K S and Suresh C H 2012 DFT study on the mechanism of water-assisted dihydrogen elimination in group 6 octahedral metal hydride complexes Dalton Trans. 4111018

46. Sandhya K S, Remya G S and Suresh C H 2015 Pincer ligand modifications to tune the activation barrier for $\mathrm{H}_{2}$ elimination in water splitting Milstein catalyst Inorg. Chem. 5411150 